\title{
Improved detection of the MUC1 cancer antigen CA 15-3 by ALYGNSA fluorimmunoassay
}

\author{
Sinang Chourb, Brian Christopher Mackness, Leslie Ruth Farris, Melisenda Jean McDonald*
}

Chemistry Department, University of Massachusetts Lowell, Lowell, USA; ${ }^{*}$ Corresponding Author: Melisenda_Mcdonald@uml.edu

Received 18 May 2011; revised 21 July 2011; accepted 28 July 2011.

\begin{abstract}
Breast cancer is the second leading cause of cancer-related deaths in women worldwide; a prime cancer biomarker to aid in the diagnosis, directed treatment, clinical management, and reoccurrence of this cancer is a MUC1 peptide fragment: cancer antigen 15-3 (CA 15-3). Herein, an immuno-fluorescence assay for CA 15-3 was developed; this ALYGNSA system consists of a protein biolinker (Protein G') adsorbed onto Poly (methyl methacrylate) (PMMA). The unique interaction of Protein G' with PMMA, a thermoplastic polymer has been demonstrated to improve human IgG capture antibody alignment/ orientation and result in greater assay sensitivity. Indeed a previous report (HEALTH 1325 329,2009 ) on the shed extracellular domain of HER-2/neu revealed a 10-fold increase in sensitivity of the ALYGSNA assay over a control ELISA assay. Results from this ALYGNSA assay study revealed that a 16-fold increase in detection ( $\leq 0.94 \mathrm{U} / \mathrm{mL}$ ) of CA $15-3$ was found in comparison to a commercial control ELISA kit ( $\leq 15 \mathrm{U} / \mathrm{mL}$ ). In conclusion, this enhanced sensitivity of the ALYGNSA assay for CA 15-3, may provide insights into the role/function of this biomarker in normal, as well as, breast cancer and other epithelial cancers.
\end{abstract}

Keywords: CA 15-3; Cancer Antigen 15-3; Epithelial Tumor Antigen; MUC1; Breast Cancer Marker; ELISA; Fluorescent Immunoassay; ALYGNSA

\section{INTRODUCTION}

Breast cancer (BC) is the second leading cause of cancer-related deaths in women worldwide after lung cancer and is the most frequently diagnosed form of cancer among American women [1]. The most frequently used and best known biomarker is Her2 [2]; this oncoprotein is cell-membrane bound but its extracellular domain is shed into circulation making it a potent biomarker used to monitor the response to treatment, and to detect recurrences in patients with diagnosed breast carcinoma $[3,4]$. However, this biomarker is only expressed in $20 \%$ of all breast tumors [5]; therefore additional $\mathrm{BC}$ markers are rigorously being explored [6]. Mucins are promising candidates [7] in particular serum CA 15-3, a MUC1 Tumor Marker; this cancer antigen is overexpressed in $>90 \%$ of breast carcinomas and metastases $[8,9]$.

The mucin protein product encoded by the MUC1 gene contains approximately $50 \%$ carbohydrate by weight with a relative molecular mass of $400 \mathrm{kDa}$ [10]. This cell surface mucin transmembrane glycoprotein, is expressed at the apical surface of most epithelia (e.g. mammary gland, female reproductive tract, stomach, etc.) in normal tissue [11]. It is comprised of three structural domains: a large and heavily O-glycosylated extracellular segment (exo-domain), a hydrophobic type 1 transmembrane region, and a short cytoplasmic tail domain involved in several signaling processes [12]. However, in cancerous tissue, this MUC-1 biomarker expression can be detected on the entire cell membrane due to transformation and loss of polarity $[13,14]$. After transport to the cell membrane, it undergoes proteolytic cleavage in which the soluble form of the large ectodomain is released into circulation [15]. The tumor marker antigen CA15-3, which corresponds to an immuno-dominant epitope in the extracellular portion of the membrane bound mucin MUC1, is shed into the bloodstream. An increase in the serum CA 15-3 shed ectodomain is associated with progression of carcinoma in patients diagnosed with breast cancer [16]. Levels of CA 15-3 measured greater than $35 \mathrm{U} / \mathrm{mL}$ are indicative of the potential progression and recurrence of breast cancer [17-19].

In this present study, an assay was developed for the detection of the breast cancer biomarker CA 15-3 utilizing the ALYGNSA system consisting of a protein biolinker (Protein G') adsorbed onto Poly (methyl methacrylate) (PMMA). The unique interaction of Protein $\mathrm{G}^{\prime}$ with PMMA, a thermoplastic polymer, has been demonstrated to improve human IgG capture antibody align- 
ment/orientation [20] and deliver greater sensitivity in the detection of several cancer biomarkers [21-24], including an additional breast cancer biomarker HER-2/ neu [21] and an additional mucin MUC16 (CA 125) [22]. Herein, this same ALYGNSA assay system will be employed to measure CA 15-3 and compare the findings to a commercial control ELISA kit.

\section{MATERIALS AND METHODS}

\subsection{CA 15-3 ELISA Assay}

This CA 15-3 ELISA assay utilizes the "sandwich" principle, where a capture antibody is directly adsorbed onto a substrate. The detector antibody is labeled with an enzyme, which upon addition of the substrate, produces a colored product quantifiable by absorbance analysis. The ELISA kit for detection of CA 15-3 purchased from BioQuant contained: microwells pre-coated with murine monoclonal anti-CA15-3 antibody, sample diluent, enzyme conjugate diluent, enzyme conjugate concentrate, tetramethylbenzidine (TMB) solution and stop solution. A range of CA 15-3 reference standards (15 - $240 \mathrm{U} / \mathrm{mL})$ provided were used directly (undiluted). This assay was performed, as closely as possible, to manufacturer's instructions. First, $200 \mu \mathrm{L}$ of CA15-3 standards was dispensed into the appropriate microwells, gently mixed for 10 seconds, and incubated at $37^{\circ} \mathrm{C}$ for 1 hour. The wells were rinsed 5 times with $\mathrm{dH}_{2} \mathrm{O}$, and $200 \mu \mathrm{L}$ of enzyme conjugate reagent was dispensed into each well followed by mixing (10 seconds) and incubation $\left(37^{\circ} \mathrm{C}\right.$ for 1 hour). The wells were re-washed and $100 \mu \mathrm{L}$ of TMB reagent was dispensed into each well and gently mixed for 10 seconds. The wells were incubated at room temperature in the dark for 20 minutes, and then finally, $100 \mu \mathrm{L}$ of stop solution was added to each well to terminate the reaction. The plate was gently mixed for 30 seconds then read at $450 \mathrm{~nm}$ with a Bio-Rad microtiter plate reader.

\subsection{CA 15-3 ALYGNSA Assay}

A "sandwich" fluoroimmunoassay which exploits unique polymer-protein noncovalent interactions between a recombinant Protein G' biolinker and a poly (methyl methacrylate) (PMMA) surface has been termed the ALYGNSA antibody-orientation system. Protein and antibody reagents used in ALYGNSA assay were: recombinant Protein G' (Pierce), Cancer Antigen 15-3 (CA 15-3) monoclonal antibodies (capture and detector) (Fitzgerald, clone\# M002204, M002208) and CA 15-3 antigen also from Fitzgerald. The Pierce 660nm Protein Assay (Product \#s: 22660, 22662) microplate format was utilized to verify protein concentrations of the CA 15-3 antibodies. The Thermo Scientific Micro BCA Protein
Assay Kit (Product \#: 23235) was used to verify recombinant Protein G' and CA 15-3 protein concentrations. Poly (methyl methacrylate) (PMMA) (Sigma) was used to coat polypropylene plates (Corning). The ALYGNSA assay protocol followed previously reported methods [25]. Briefly, the PMMA plates were coated with recombinant Protein G' $(1 \mu \mathrm{g} / \mathrm{mL}$ at $50 \mu \mathrm{L} /$ well $)$ and incubated overnight at $4{ }^{\circ} \mathrm{C}$. After washing once with TBST, the plates were coated with the capture CA 15-3 antibody at $5 \mu \mathrm{g} / \mathrm{mL}$ at $50 \mu \mathrm{L} /$ well and incubated overnight at $4^{\circ} \mathrm{C}$. After washing, the plates were blocked with 5\% non-fat dry milk (NFDM) for 1 hour at room temperature and washed. The CA 15-3 antigen was diluted to $60 \mathrm{U} / \mathrm{mL}$ in PBS and $100 \mu \mathrm{L}$ was applied to the top rows of each plate. A 1:1 serial dilution in PBS was performed and carried out to $0.94 \mathrm{U} / \mathrm{mL}$. The plates were then incubated for 2 hours at room temperature, and then washed. The fluorescently labeled CA 15-3 detector antibody prepared by the DyLight 488 Microscale Antibody Labeling Kit as recently described [25] was diluted to $5 \mu \mathrm{g} / \mathrm{mL}$, and applied at $50 \mu \mathrm{L} /$ well. Following incubation for 1 hour at room temperature and a repeat washing, the plates were read for fluorescence at $485 / 523 \mathrm{~nm}$ on a BioTek Microplate Reader.

\section{RESULTS and DISCUSSION}

\subsection{ELISA and ALYGNSA Immunoassays}

Enzyme-Linked Immunosorbant Assay (ELISA) is a common immunochemical colorimetric method used to detect cancer biomarkers in biological fluids, such as serum [16,26]. The CA 15-3 ELISA assay utilizes the "sandwich" principle, where a capture antibody is directly adsorbed onto a substrate. The detector antibody is labeled with an enzyme, which upon addition of the substrate, produces a colored product quantifiable by absorbance analysis. A comparison of 15 commercial immunoassays for detection of CA15-3 (MUC1) in serum has been reported with manufacturer cut-off ranging from 23 - 39 (U/mL) [27]. A BioQuant ELISA kit was employed in the present study. After multiple runs of this commercial CA 15-3 ELISA kit assay, the Limit $\underline{\text { Of }}$ Detection (LOD) for CA 15-3 protein, in our hands, was determined to be $\leq 15 \mathrm{U} / \mathrm{mL}$ (Figure 1; Table 1); it is interesting to note that this is below the cutoff of $17 \mathrm{U} / \mathrm{mL}$ (reported range $5-47 \mathrm{U} / \mathrm{mL}$ ) for the non-cancerous state [28].

For more efficacy of the use of proteins and antibodies, an alternative form of this assay, a fluorescent ALYGNSA assay was employed [20]. The ALYGNSA assay format is essentially the same as the colorimetric ELISA; to further enhance sensitivity of the assay, a properly 


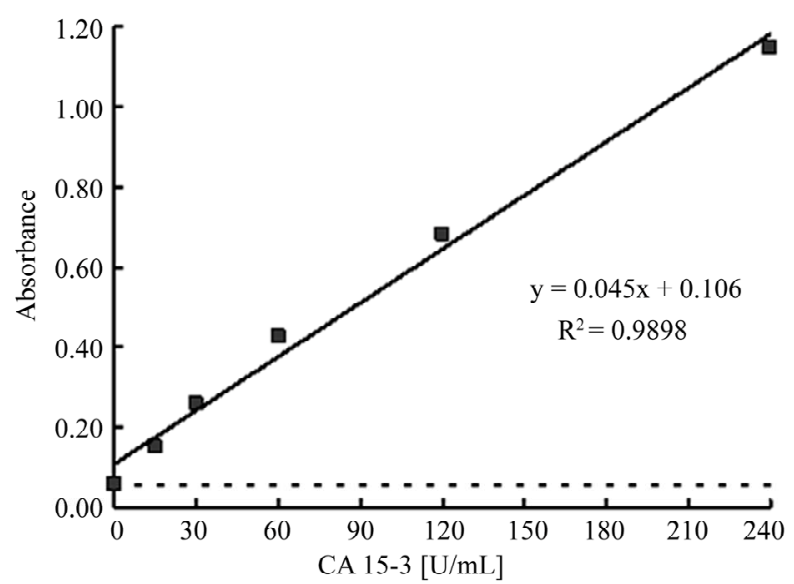

Figure 1. BioQuant CA 15-3 ELISA: Results for assay (-匹-m-) and baseline (------) points. The standard deviation values are presented in Table 1. Each data point represents the average of five replicates. The LOD was determined by the blank plus two times the standard deviation of the blank value and was $15 \mathrm{U} / \mathrm{mL}$.

Table 1. BioQuant CA 15-3 ELISA.

\begin{tabular}{cccc}
\hline [CA 15-3] U/mL & Absorbance & \pm SD & $\% \mathrm{CV}$ \\
\hline 240 & 1.020 & 0.21 & 20 \\
120 & 0.628 & 0.08 & 13 \\
60 & 0.426 & 0.00 & 0 \\
30 & 0.225 & 0.05 & 22 \\
$\mathbf{1 5}^{*}$ & $\mathbf{0 . 1 3 8}$ & $\mathbf{0 . 0 2}$ & $\mathbf{1 2}$ \\
0 & 0.054 & 0.01 & 9 \\
\hline
\end{tabular}

*Level of Detection (LOD) was $\leq 15 \mathrm{U} / \mathrm{mL}$ and was defined as the blank + 2 standard deviations (SD) [24].The intra-assay variability (\%CV) or $[$ (standard deviation $/$ mean $) \times 100]$ was calculated based on the difference in multiple measurements.

aligned capture antibody is the primary key. To successfully achieve this "alignment", a recombinant Streptococcal protein $\mathrm{G}^{\prime}$ is utilized. Protein G' binds to the Fc region of the capture antibody, in this case murine $\mathrm{IgG}$, allowing optimal interaction of the antigen-binding arms with antigens, and in turn, increases the detection ability of the antibody. The ALYGNSA assay for CA 15-3 detection employs a sandwich assay protocol similar to the commercial ELISA described above. Multiple determinations with the CA 15-3 ALYGNSA assay system revealed an assay LOD of $\leq 0.94 \mathrm{U} / \mathrm{mL}$ for detection of CA 15-3 (Figure 2; Table 2). These results indicated a 16-fold greater sensitivity for the CA 15-3 ALYGNSA assays as compared to the BioQuant ELISA.

\subsection{Structure of Extracellular Domain of MUC1: Potential for Vaccine Development}

The large extracellular tandem repeat domain is highly

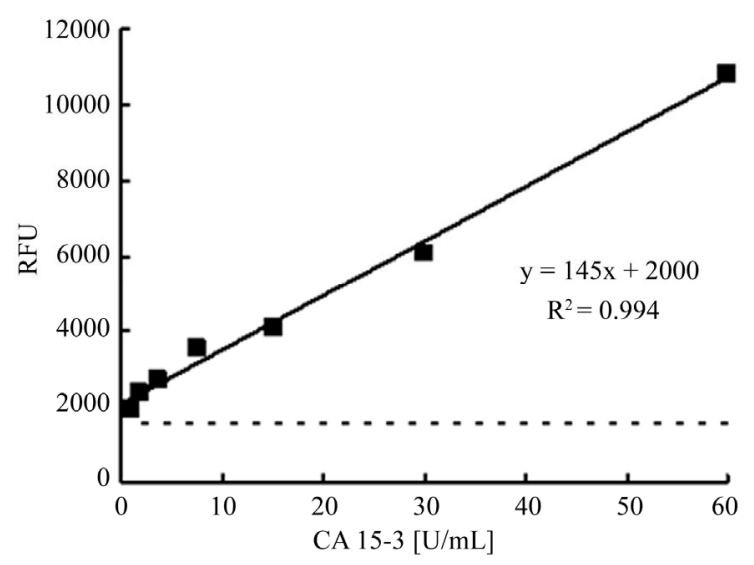

Figure 2. CA 15-3 ALYGNSA Assay: ALYGNSA assay results (-m-m-) and baseline (-----) points. The standard deviation values are presented in Table 2 . Each data point represents the average of six replicates. The LOD, as defined previously in Figure 1 was $0.94 \mathrm{U} / \mathrm{mL}$.

Table 2. CA 15-3 ALYGNSA assay.

\begin{tabular}{cccc}
\hline$[\mathrm{CA} 15-3] \mathrm{U} / \mathrm{mL}$ & Fluorescence & $\pm \mathrm{SD}$ & $\% \mathrm{CV}$ \\
\hline 60 & 11480 & 947 & 8 \\
30 & 6570 & 619 & 11 \\
15 & 5010 & 47 & 1 \\
7.5 & 3720 & 693 & 19 \\
3.8 & 2900 & 690 & 24 \\
$\mathbf{0 . 9 4 *}$ & $\mathbf{1 7 5 0}$ & $\mathbf{4 1 5}$ & $\mathbf{2 4}$ \\
0 & 1550 & 49 & 3
\end{tabular}

*Level of Detection (LOD) was $\leq 0.94 \mathrm{U} / \mathrm{mL}$ as defined earlier in Table 1. The $\% \mathrm{CV}$ was calculated as described in Table 1; value and SD of blank were consistent with previously published reports [21-24].

O-glycosylated and alterations in glycosylation have been shown in epithelial cancer cells $[12,29]$. Repeats of the core protein give rise to a relatively rigid, linear structure protruding $200-500 \mathrm{~nm}$ above the cell surface $[15,30]$. The structure of the extracellular subunit includes a region of nearly identical tandem repeats of 20 amino acids, with variable number $(20$ - 125) of repeats (VNTR). This highly conserved tandem repeat region of CA 15-3 has been proposed to be evaluated as a vaccine for breast cancer by a number of clinical trials [7,16,31]. Vaccine development requires a dynamic detection range. Improved sensitivity as seen with our assay is vital for the success of these new treatment options.

\subsection{MUC1/CA 15-3 Function: Improved Research Capability through Increased Sensitivity}

The MUC1 gene encodes the CA 15-3 protein that is generally expressed in different levels on the apical sur- 
face of many normal and malignant epithelial cells (expression over entire cell surface), including in the mammary gland, female reproductive tract, lung, kidney, stomach, gall bladder and pancreas, as well as, some nonepithelial cell types [7-9,31,32]. The precise function of CA 15-3 is unclear, although in general, the physiological function of mucins is in lubrication and hydration of cell surfaces, protection of proteins and cells from proteolysis and in the protection of tissues from microbial attack. However, other evidence suggests CA 15-3 appears to play a role in cell-adhesion, where it modulates cell-cell and cell-extracellular matrix (ECM) interactions. In addition to its function as a protective barrier with adhesion-modulating properties, the CA 15-3 cytoplasmic tail has the potential role in cell signal transduction and has been reported to contribute to metastases [32,33]. Increased assay sensitivity offers improved expression analysis for researchers working to identify the function of mucin protein MUC1. Further understanding of this protein may lead to the development of personalized treatment and preventative medicines.

\section{CONCLUSIONS}

In summary, our work utilized a fluorescent ELISA incorporating the newly developed ALYGNSA antibodyorientation system has revealed a 16-fold increase in sensitivity $(\leq 0.94 \mathrm{U} / \mathrm{mL})$ of CA $15-3$ when compared to a commercial ELISA kit $(\leq 15 \mathrm{U} / \mathrm{mL})$. The ALYGNSA assay could aid in evaluation and detection of CA 15-3 under normal conditions, be useful for surveillance of patients diagnosed with breast cancer and to monitor the course of therapy in advanced disease. Furthermore, an increase in sensitivity of the CA 15-3 assay for detection of the shed extracellular domain containing the VNTR region, may provide additional insights into the role/ function and clinical assessment of CA 15-3 in breast cancer and other epithelial expressing this protein. Finally, this system has the potential to be incorporated into a cost-effective biosensor device [34]. This noninvasive serum-based test platform would assist in earlystage cancer diagnosis allowing the clinician to respond in $a$ proactive rather than a reactive manner.

\section{ACKNOWLEDGEMENTS}

This work was supported by NSF award \# 0425826. Special thanks to Adrianna Morris and Peter S. Chiev for their support and critical reading of this manuscript.

\section{REFERENCES}

[1] Jemal, A., Siegel, R., Xu, J. and Ward, E. (2010) Cancer Statics. CA Cancer Journal for Clinicians, 60, 277-300. doi: $10.3322 /$ caac. 20073
[2] Moelans, C.B., de Weger, R.A., Van der Wall, E. and van Diest, P.J. (2011) Current technologies for HER2 testing in breast cancer. Critical Reviews in Oncology/Hematology, Accessed May 5, 2011. doi:10.1074/mcp.R400001-MCP200

[3] Ross, J.S., Fletcher, J.A., Linette, G.P., Stec, J., Clark, E., Ayers, M., et al. (2004) Targeted therapy in breast cancer: The HER-2/neu gene and protein. Molecular \& Cellular Proteomics, 3, 379-398. doi:10.1074/mcp.R400001-MCP200

[4] Bramwell, V.H.C., Doig, G.S., Tuck, A.B., Wilson, S.M., Tonkin, K.S., Tomiak, A., et al. (2009) Changes over time of extracellular domain of HER2 (ECD/HER2) serum levels have prognostic value in metastatic breast cancer. Breast Cancer Research and Treatment, 114, 503-511. doi:10.1007/s10549-008-0033-2

[5] Carney, W.P., Leitzel, K., Ali, S., Neumann, R. and Lipton, A. (2007) HER-2/neu diagnostics in breast cancer. Breast Cancer Research, 9, 207-217. doi:10.1186/bcr1664

[6] Jones, S.E. (2008) Metastatic breast cancer: The treatment challenge. Clinical Breast Cancer, 8, 224-233. doi:10.1038/nrc2761

[7] Mukhopadhyay, P., Chakraborty, S., Ponnusamy, M.P., Lakshmanan, I., Jain, M. and Batra, S. K. (2011) Mucins in the pathogenesis of breast cancer: Implications in diagnosis, prognosis and therapy. Biochimica et Biophysica Acta, 1815, 224-240.

[8] Kufe, D.W. (2009) Mucins in cancer: Function, prognosis and therapy. Nature Reviews Cancer, 9, 874-885. doi:10.1016/j.tibs.2009.10.003

[9] Senapati, S., Das, S. and Batra, S.K. (2010) Mucin-interacting proteins: From function to therapeutics. Trends in Biochemical Sciences, 35, 236-245. doi:10.1016/j.tibs.2009.10.003

[10] Duffy, M.J. (1999) CA 15-3 and related mucins as circulating markers in breast cancer. Annals of Clinical Biochemistry, 36, 579-586.

[11] Bafna, S., Kaur, S. and Batra, S.K. (2010) Membrane-bound mucins: The mechanistic basis for alterations in the growth and survival of cancer cells. Oncogene, 29, 2893-2904. doi:10.1038/onc.2010.87

[12] Lagow, E., DeSouza, M.M. and Carson, D.D. (1999) Mammalian reproductive tract mucins. Human Reproduction, 15, 280-292.

[13] Agrawal, B., Gendler, S.J. and Longenecker, B.M. (1998) The biological role of mucins in cellular interactions and immune regulation: Prospects for cancer immunotherapy. Molecular Medicine Today, 4, 397-403. doi:10.1016/S1357-4310(98)01322-7

[14] Brayman, M., Thathiah, A. and Carson, D.D. (2004) MUC1: A multifunctional cell surface component of reproductive tissue epithelia. Reproductive Biology and Endocrinology, 2, 1-9. doi:10.1186/1477-7827-2-4

[15] Parry, S., Silverman, H.S., McDermott, K., Willis, A., Hollingsworth, M.A. and Harris, A. (2001) Identification of MUC1 proteolytic cleavage sites in vivo. Biochemical and Biophysical Research Communications, 283, 715720. doi:10.1006/bbrc. 2001.4775

[16] Welsh, J.B., Sapinoso, L.M., Kern, S.G., Brown, D.A., Liu, T., Bauskin, A.R., et al. (2003) Large-scale delineation of secreted protein biomarkers overexpressed in 
cancer tissue and serum. Proceedings of the National Academy of Sciences USA, 100, 3410-3415. doi:10.1073/pnas.0530278100

[17] Duffy, M.J., Duggan, C., Keane, R., Hill, A.D.K., McDermott, E., Crown, J. and O'Higgins, N. (2004) High preoperative CA 15-3 concentrations predict adverse outcome in node-negative and node-positive breast cancer: Study of 600 patients with histologically confirmed breast cancer. Clinical Chemistry, 50, 559-563. doi:10.1373/clinchem.2003.025288

[18] Tampellini, M., Berruti, A., Gerbino, A., Buniva, T., Torta, M., Gorzegno, G., et al. (1997) Relationship between CA 15-3 serum levels and disease extent in predicting overall survival of breast cancer patients with newly diagnosed metastatic disease. British Journal of Cancer, 75, 698-702. doi:10.1038/bjc.1997.124

[19] Kim, H.S., Park, Y.H., Park, M.J., Chang, M.H., Jun, H.J., Kim, K.H., et al. (2009) Clinical significance of a serum CA15-3 surge and the usefulness of CA15-3 kinetics in monitoring chemotherapy response in patients with metastatic breast cancer. Breast Cancer Research and Treatment, 118, 89-90. doi:10.1007/s10549-009-0377-2

[20] Clarizia, L.-J.A., Sok, D., Wei, M., Mead, J., Barry, C. and McDonald, M.J. (2009) Antibody orientation enhanced by selective polymer-protein noncovalent interactions. Analytical and Bioanalytical Chemistry, 393, 1531-1538. doi:10.1007/s00216-008-2567-x

[21] Chourb, S., Mackness, B.C., Farris, L.R. and McDonald, M.J. (2009) Enhanced immuno-detection of shed extracellular domain of HER-2/neu. Health, 1, 325-329. doi:10.4236/health.2009.14053

[22] Sok, D., Clarizia, L.-J.A., Farris, L.R. and McDonald, M.J. (2009) Novel fluoroimmunoassay for ovarian cancer biomarker CA-125. Analytical and Bioanalytical Chemistry, 393, 1521-1523. doi:10.1007/s00216-008-2569-8

[23] Mackness, B.C., Chourb, S., Farris, L.R. and McDonald, M.J. (2010) Polymer-protein-enhanced fluoroimmunoassay for prostate-specific antigen. Analytical and Bioanalytical Chemistry, 396, 681-686. doi:10.1007/s00216-009-3234-6

[24] Mackness, B.C. and McDonald, M.J. (2010) Serum-Based ALYGNSA immunoassay for the prostate cancer biomarker, total prostate-specific antigen (tPSA). Analytical and Bioanalytical Chemistry, 397, 3151-3154. doi:10.1007/s00216-010-3827-0

[25] Chourb, S. (2010) Enhanced immuno-detection of breast cancer biomarkers: Shed extracellular domain of Her-2/ neu and CA 15-3. Master's Thesis, University of Massachusetts Lowell, Lowell.

[26] Sturgeon, C.M., Duffy, M.J., Stenman, U.H., Lilja, H., Brünner, N., Chan, D.W., et al. (2008) National Academy of Clinical Biochemistry Laboratory Medicine Practice Guidelines for use of tumor markers in prostate, colorectal, breast and ovarian cancers. Clinical Chemistry, 54, e11-e79. doi:10.1373/clinchem.2008.105601

[27] Pichon, M.F., Brun, G.L., Hacene, K., Basuyau, J.P., Riedinger, J.M., Eche, N., Fulla, Y. and Charlier-Bret, N., (2009) Comparison of fifteen immunoassays for the measurement of serum MUC-1/CA 15-3 in breast cancer patients. Clinical Chemistry and Laboratory Medicine, 47, 985-992. doi:10.1515/CCLM.2009.213

[28] Bon, G.G., Kenemans, P., Dekker, J.J., Hompes, P.G., Verstraeten, R.A., van Kamp, G.J. and Schoemaker, J. (1999) Fluctuations in CA 125 and CA 15-3 serum concentrations during spontaneous ovulatory cycles. Human Reproduction, 14, 566-570. doi:10.1093/humrep/14.2.566

[29] Jonckheere, N. and Van Seuningen, I. (2010) The membranebound mucins: From cell signaling to transcriptional regulation and expression in epithelial cancers. Biochimie, 92, 1-11. doi:10.1016/j.biochi.2009.09.018

[30] Hattrup, C.L. and Gendler, S.J. (2008) Structure and function of the cell surface (tethered) mucins. Annual Review of Physiology, 70, 431-457. doi:10.1146/annurev.physiol.70.113006.100659

[31] Yuan, S., Shi, C., Ling, R., Wang, T., Wang, H. and Han, W. (2010) Immunization with two recombinant bacillus calmette-guerin vaccines that combine the expression of multiple tandem repeats of mucin-1 and colony stimulating-factor suppress breast tumor growth in mice. Journal of Cancer Research and Clinical Oncology, 136, 13591367. doi:10.1007/s00432-010-0787-x

[32] Thie, H., Toleikis, L., Li, J., von Wasielewski, R., Bastert, G., Schirrmann, T., et al. (2011) Rise and fall of an Anti-MUC1 specific antibody. PLOS ONE, 6, Article Number: e15921. doi:10.1371/journal.pone.0015921

[33] Hanash, S.M., Baik, C.S. and Kallioniemi, O. (2011) Emerging molecular biomarkers-Blood-based strategies to detect and monitor cancer. Nature Reviews Clinical Oncology, 8, 142-150. doi:10.1038/nrclinonc.2010.220

[34] Bohunicky, B. and Mousa, S.A. (2011) Biosensors: The new wave in cancer diagnosis. Nanotechnology, Science and Applications, 4, 1-10. 